\title{
'|||||||||||||||||||||||||||||||||||||||||||||||||||||||||||||||||||.
}

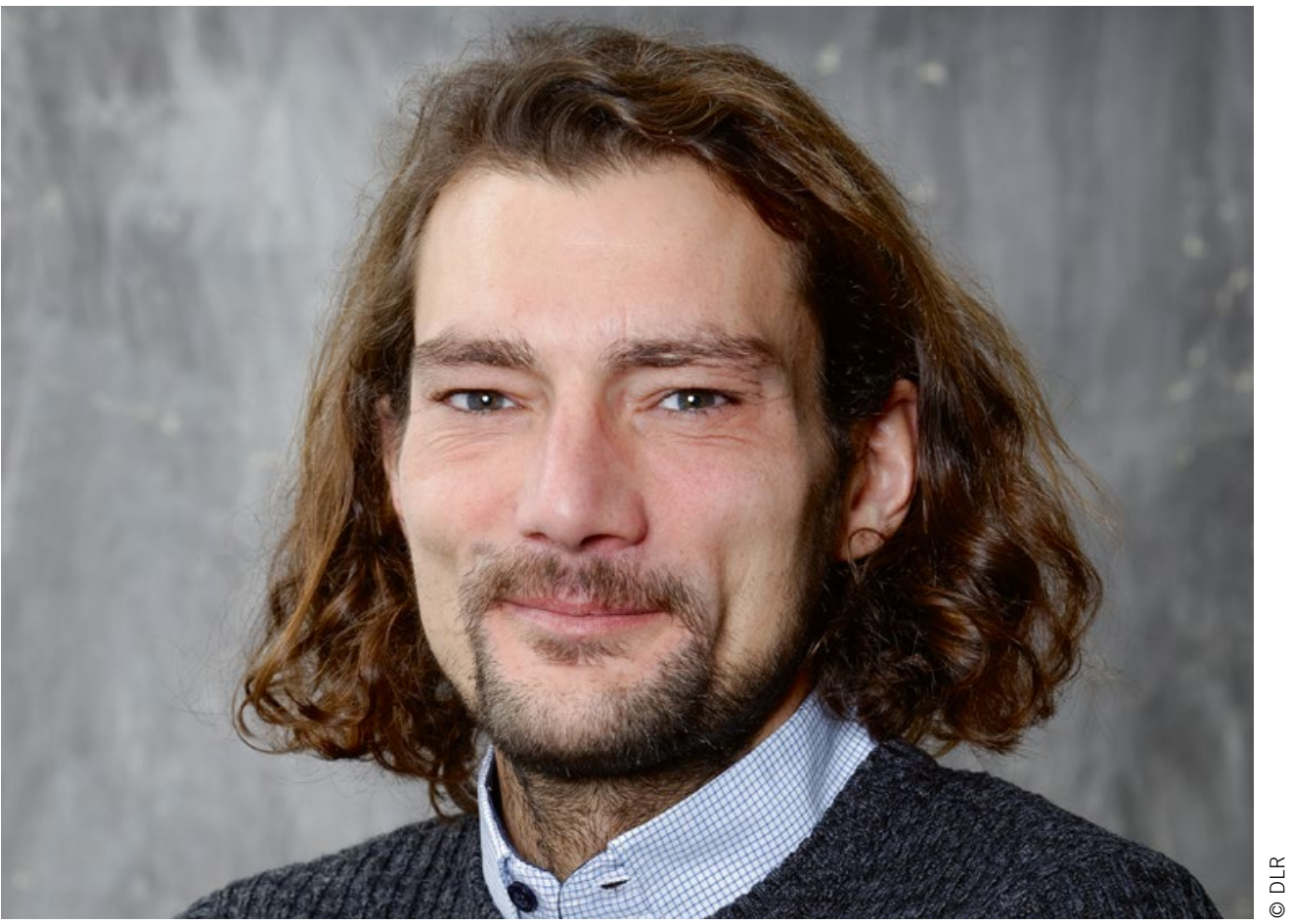

Dr.-Ing. Stephan Müller Research Associate of the Institute of Transport Research at the German Aerospace Center (DLR)

\section{Driverless Trucks in Ten Years - What the Logistics Industry Needs}

With regard to automated and connected driving in the truck market, vehicle manufacturers have concentrated on developing trucks for two areas of application in the past: firstly, platooning (convoy driving or electronic tiller), where it is possible to drive safely at a significantly reduced distance one after another, and secondly, the mobile office, where the driver can carry out other activities such as scheduling appointments or talking to customers while the vehicle takes over the driving task.

However, our research at DLR in the ATLaS project shows that this orientation of technology development is of less relevance to customers in the logistics industry. The reasons for this are manifold and range from "We cannot buy expensive technology to make it more comfortable for the driver at work" to "Our customer's need the ordered quantity on time and not three truckloads bundled in a convoy driving up to the ramp."

Nevertheless, the possibility of automated and connected driving is generally meeting with enormous interest in the logistics industry. It is expected that the technology can provide an answer to two key challenges facing the industry: the growing shortage of driver counts and increasing cost pressure with low margins. On the demand side, this results in a very concrete technology requirement: According to our research results, driverless semitrailers are needed. And these would have to be available and reliable in ten years. This is because a solution to the before-mentioned challenges must be developed within this period. The main area of application for driverless semitrailers is in general cargo, for example night-time transport. "The more standardized the logistics process, the more likely it is that driverless trucks can be applied," was how a top manager from one of the logistics companies we surveyed summed it up.

The good news for vehicle manufacturers is therefore: With the right technology, they can tap into an enormous market potential. To achieve this, the current introduction strategy of the technology little by little in the truck market must be abstained. This means that small steps from SAE level 2+ do not help. The necessary strategy here is rather to make a direct technological leap to driverless trucks. Rather, the necessary strategy here lies in the direct technological leap to driverless trucks. OEMs must therefore weigh up promptly whether the associated high investment in research and development in the relatively short time window of ten years is feasible and promising. 